Population modelling: how are large mammals different?

\section{Hans Kruuk}

\author{
Dynamics of Large Mammal Populations. \\ Edited by Charles W. Fowler and Tim D. \\ Smith. Pp.477. ISBN 0-471-05160-8. \\ (Wiley: 1982.) £33.25, \$56.55.
}

FOR several decades population models have been generally successfully used in the rational exploitation of fish stocks. Such models focus on productivity, and each involves only a single species. In Dynamics of Large Mammal Populations the editors argue that large mammals are different from other animals in their population characteristics; reading through the various chapters, however, it appears that often the approach to population research is the same as in fisheries. Many of the species discussed are being "harvested", and population models are directed towards maximum sustainable yield, with many of the characteristics of fisheries models.

However, as pointed out by G. Caughley in this volume, single-species models may serve exploitation but they do not explain ecological relationships. It is in the relationships with their environment that large mammals differ from other organisms, as argued in the chapter by R.M. Laws (to whom the book is dedicated); as a group they show similarity in feeding strategies, social behaviour, reproduction and demographic parameters. These aspects of large mammal biology have evolved together and it is dangerous to focus on merely the last of them.

The book contains 23 chapters, many with detailed single-species population models, and several general sections on modelling and management. On the whole the contributions are slanted towards marine species, especially seals; several chapters deal with terrestrial carnivores, but the many studies on herbivores (African bovids; deer, sheep) are poorly represented. Generally, there is little crossreference between chapters, even to the extent that two different sections on models of the Pribilof fur-seal exploitation hardly refer to each other at all. There are no summaries, which makes reading of this kind of material cumbersome.

Highlights amongst the contributions are a section "What we don't know about

\begin{tabular}{|l|}
\hline Pergamon journals \\
Incorrect dollar subscription rates were \\
quoted for four Pergamon journals in the \\
recent New Journals review issue of Nature \\
(299, pp.507,510, 511 and 514). \\
Correct prices (for 1983) are: Insect \\
Science and Its Application \$85; Chinese \\
Astronomy and Astrophysics \$200; \\
PhysicoChemical Hydrodynamics \$120; \\
Bulletin of Science, Technology and Society \\
\$85. \\
\hline
\end{tabular}

the dynamics of large mammals", which details the complexity of even the simplest herbivore-plant interaction in terms of populations; there is also a good comparison of population characteristics of three species of bear, an excellent evaluation of management policies of gray seals and a clearly written decision-making framework for population management. Inevitably there are weak points, too; some of the models presented in the singlespecies sections make assumptions which are either hopelessly unrealistic or so general as to make the model useless and recommendations impractical. Thus, a model of wolf-moose interactions recommends an optimal moose harvest under conditions whereby wolves are either left alone or controlled only when there are few of them; even the authors were unhappy with that conclusion.
With a few notable exceptions the papers on population dynamics of specific mammals are inward-looking, singlespecies studies. The often-used concept of density-dependence hides possible dependence on restricted resources in the animal's environment; in the last, theoretical chapter, for instance, it is found after a long and involved argument that densitydependent changes occur in populations close to carrying capacity. Clearly, there is no true density-dependence in such cases, but dependence on, for example, populations of food species.

In all the editors have missed the opportunity to push studies of large mammal populations further along by at least attempting to integrate papers dealing with exploitation with others on resource limitations and utilization. If one is interested in managing the productivity of large mammal populations, however, this volume does provide a great deal of food for thought.

Hans Kruuk is a Principal Scientific Officer at the Institute of Terrestrial Ecology, Banchory, Scotland.

\title{
Resolving problems in spectroscopy
}

\section{Norman Sheppard}

High Resolution Spectroscopy. By J. Michael Hollas. Pp.638. ISBN 0-40810605-0. (Butterworths: 1982.) £45, \$115.

DURING the past decade the subject of molecular spectroscopy has been revitalized by the development of a wide range of new techniques. Michael Hollas's book represents a timely attempt to provide a comprehensive and balanced account of both these and the more established principles of the subject.

In the preface the author states that "In general . . . the sample is assumed to be in the gas or vapour phase"; indeed, an alternative and more accurate, if perhaps less eye-catching, title for the book could have been Molecular Spectroscopy of Gases. Under this rubric the exclusion of the magnetic resonance spectroscopies (little applied to gases) and the inclusion for very good pedagogical reasons - of photoelectron spectra of gases would have been naturally assumed. Under the present title these two aspects of the book seem to be very anomalous, for the magnetic resonance spectroscopies are of very high resolution, and photoelectron spectra are much less so than others.

Naturally, a particularly interesting section of the book is concerned with those newer developments that are not, or are little, covered in existing comprehensive spectroscopy textbooks. The last two chapters - some 160 pages - are mainly devoted to such topics, including the laser and photoelectron spectroscopies, and provide a welcome and well-balanced account of the recent advances. The earlier chapters cover more familiar ground but also provide up-to-date treatments of the subject-matter.

The book covers both experimental and theoretical/interpretational aspects of the molecular spectroscopies and has wellchosen spectral illustrations. In general the writing is well-planned and clear, careful attention has been paid to detail and there are some nice historical touches. The occasional helpful footnote shows that the author is a naturally skilled teacher.

Perfection is not to be expected in a book of such wide coverage. For example, as a vibrational spectroscopist, I note that it is a mistake to use the phrase "near-infrared" to cover all that is not "far-infrared". The normal usage of the former phrase is restricted to the high frequency overtone region - the intervening region of fundamental vibrations is nowadays termed the "mid-infrared". I was also surprised to find a comment to the effect (p.176) that the use of rotational contours in infrared vibration spectra is not a "standard" technique for identifying (the symmetries of) fundamentals - it most certainly is, despite some complications.

These are, however, minor criticisms of what is overall a very successful text. The book deserves wide usage by its intended readership of undergraduates specializing in spectroscopy, and postgraduate students and teachers of the subject.

Norman Sheppard is a Professor in the School of Chemical Sciences at the University of East Anglia. 